\title{
La institucionalización de dos prácticas de la psicología en Chile: la psicología Comunitaria y la psicología de los Derechos Humanos
}

Isabel Piper ${ }^{26}$

\section{Resumen}

Este texto reconstruye algunos aspectos de la memoria de dos espacios críticos del ejercicio de la psicología en Chile: la Psicología Social Comunitaria y la Psicología de los Derechos Humanos. Se reflexiona sobre el carácter "crítico" de dichas prácticas, a partir de un análisis de las condiciones sociales en las que fueron efectivamente alternativas a la psicología dominante y prácticas de resistencia política a las condiciones de la época.

Palabras clave: psicología crítica, psicología comunitaria, intervención social, derechos humanos, reparación, transformación social.

\begin{abstract}
This paper presents the reconstruction of some aspects of the practice of Chilean psychology in two critical areas; Community Social Psychology and Human Rights Psychology. It discusses the character of these practices which arose during the 1960s and 1970s as an expression of dissent. It is suggested that they were the result of certain social conditions in which they actually represented alternatives to the dominant forms of psychology, and practices of political resistance to the social conditions prevailing at that time.

Keywords: critical psychology, community psychology, social intervention, human rights, atonement, social transformation.
\end{abstract}

26 Doctora en Psicología Social, Académica del Departamento de Psicología, Universidad de Chile.ipiper@uchile.cl 


\section{Introducción}

Si es que existe algo en común entre psicólogos de distinto tipo, (clínicos, sociales o laborales; individuales, grupales o comunitarios; jóvenes o viejos; psicoanalistas, conductistas o humanistas; progresistas o conservadores; críticos o no) son las buenas intenciones con las que llevan a cabo su trabajo. Suelen preocuparse de los problemas y las necesidades de la gente, buscan ayudar a los que sufren y a menudo tratan de cambiar las situaciones que perjudican el bienestar de las personas. Bastante menos generalizado es el deseo de transformar nuestras sociedades, de desarrollar la justicia y la libertad para nuestros pueblos. $\mathrm{Si}$ a las buenas intenciones le sumamos esta voluntad, entonces nos encontramos con una psicología comprometida con los procesos sociales y políticos en los que está inmersa. El compromiso es con las víctimas de injusticias, con los que sufren, los que han sido marginados tanto por la sociedad como por los científicos. Se critica la realidad y también la psicología por no ser capaz de dar cuenta ella, se construye una práctica de la disciplina que desde sus orígenes se sabe movida por la voluntad de ser disidente: con su sociedad y con su disciplina.

Siendo disidentes desde la psicología se han realizado aportes importantes que han legitimado la existencia de dichas prácticas frente a los distintos actores involucrados, y que han satisfecho muchas buenas intenciones, pese a que las condiciones de emergencia en las que se ha llevado a cabo este trabajo hayan dificultado su desarrollo conceptual y la hayan posicionado en la inmediatez fáctica de los problemas urgentes, que demasiadas veces han impedido reflexionar críticamente en la propia práctica. Sin embargo ahora, en un principio de siglo consensual, en un país con escasos y débiles movimientos sociales, donde la política es un espacio deslegitimado y frustrante, ha empezado a surgir una disidencia preocupada de sus fundamentos teóricos, que no solo se posiciona críticamente frente a la psicología tradicional sino también a la realización efectiva de aquellas psicologías disidencias disidentes que fueron hasta hace poco referentes de la crítica en nuestro país.

Este texto reconstruye memoria de dos espacios críticos de psicologías chilenas: la Psicología Social Comunitaria y la Psicología de los Derechos Humanos. A partir de algunas notas tomadas de las narrativas que ellas mismas construyen sobre su desarrollo, analizaré el carácter efectivo de esas prácticas que surgen diciéndose disidentes, que se dicen (y/o son dichas) críticas. 


\section{Psicología Social Comunitaria en Chile El surgimiento de una práctica crítica}

A partir de los años sesenta se han desarrollado en Chile experiencias de intervención social ${ }^{27}$ de carácter innovador en relación con las prácticas hegemónicas del momento. La crítica surge al interior de los hospitales psiquiátricos y es liderada por médicos que buscan modelos teóricos y prácticos que permitan responder a los problemas de salud de los sectores más marginados del país. Dichas experiencias son frecuentemente señaladas como las bases sobre las cuales se gestarían diversas prácticas psicosociales que posteriormente se agruparían bajo el nombre de Psicología Social Comunitaria.

A partir de la crítica al quehacer hegemónico en este ámbito, considerado como ajeno a a las necesidades de las mayorías, se articulan diversas intervenciones puestas al servicio de quienes son definidos por esos profesionales como los más necesitados. El quehacer fue desde un principio heterogéneo: se utilizan de técnicas de educación popular; procesos de concientización social y política; formación de redes sociales de apoyo; talleres grupales de capacitación para el trabajo, de desarrollo personal o de búsqueda de salud integral; grupos de autoayuda para mujeres maltratadas, adictos y sus familiares o enfermos crónicos; terapias individuales, familiares o grupales realizadas en zonas de extrema pobreza; intervenciones participativas; procesos de empoderamiento; entre otros.

Durante la Dictadura Militar (1973-1989) muchas de esas prácticas se cruzaban y diluían con actividades partidistas y/o de religiosidad popular realizadas clandestinamente bajo el amparo de la Iglesia católica. Las intervenciones psicosociales o comunitarias buscaban acercar a la ciencia (o las profesiones) a las necesidades reales de la población, ayudando a resolver problemas urgentes de supervivencia en condiciones políticas, sociales y económicas críticas. La diversidad de demandas obligaba a articular distintos tipos de estrategias de acción, realizadas con muy pocos recursos materiales y en condiciones adversas, lo que dejaba poco tiempo y espacio para sistematizar y coordinar las intervenciones y mucho menos para el desarrollo de conceptos y teorías. Sus actividades son más fácilmente caracterizables en términos de la práctica efectiva, de los objetivos y valores en los que basan, que a través de sus conceptos, ya que la construcción teórica ha ido siempre en este campo a remolque de la acción (Sánchez Vidal, 1991). Las fuentes

27 En ese momento no eran denominadas así, aunque hoy lo son de manera retrospectiva. Existe actualmente una cierta reticencia a utilizar el apelativo de Psicología Comunitaria. En cambio, la tendencia es referirse a nombres como Modelo Comunitario, Psicología Social, Intervenciones Psicosociales o Psiquiatría Comunitaria. Eso no significa que no se recurra al término Comunitario, que se usa de manera difusa para referirse a prácticas que van desde Educación Popular hasta prácticas de salud pública. 
de legitimación de esta Psicología han radicado principalmente en sus prácticas participativas y autogestionarias, que han sido no solo su ámbito de acción, sino también su justificación y su carta de presentación.

La forma de Psicología Social Crítica llamada Psicología Comunitaria, se constituye (al menos en Chile) desde la práctica y no logra desarrollar más que conceptos vagos, heterogéneos e inconexos. La crítica ha operado bajo la forma de propuestas fácticas, de búsqueda de resultados inmediatos, de resolución de problemas urgentes, evitando encasillarse en conceptos que amenazaran con restringir sus prácticas, y postergando la producción conceptual y de reflexiones teóricamente sustentadas.

Aunque se han realizado múltiples y diversos intentos por sistematizar, compartir, establecer diálogos e investigar las prácticas comunitarias, sus elaboraciones teóricas siguen siendo postergadas. En un análisis de la Psicología Comunitaria chilena realizado en 1994, Maritza Montero sostiene que ésta busca concretar prácticas e intervenciones psicosociales omitiendo un análisis respecto a los fundamentos teóricos que la sustentan. "Nos encontramos en un caso en el que no está explicitado el marco teórico, más aún, no hay una relación entre la praxis y la generación de conocimiento científico" (Montero, 1994). Hasta hoy son escasos los cuestionamientos acerca de la pertinencia y los efectos de la labor comunitaria. Son grandes los vacíos conceptuales de sus opciones, las que dicen sustentarse en nociones como las de participación o autogestión (entre otras), pero que al carecer de un trasfondo de reflexión se han instalado como palabras vacías de referentes.

Lo expuesto hasta aquí sugiere que la fuerza de las prácticas comunitarias no está en sus bases conceptuales, referentes teóricos, métodos de trabajo o técnicas de intervención. No está en la calidad de sus experiencias, ni tampoco en alguna cualidad de ella. No se encuentra en el éxito de sus intervenciones ni en su capacidad de contribuir a la transformación social (lo que al menos hasta ahora no ha podido ser mostrado). Al parecer su fuerza está en la voluntad crítica y transformadora de sus actores y en el deseo de articular prácticas que en ciertos contextos han resultado efectivamente disidentes.

La voluntad de desarrollar un ámbito disciplinar alternativo a la psicología tradicional ha sido tan fuerte que, pese a la falta de reflexión teórica y conceptual, este conjunto de prácticas ha sostenido hasta ahora un discurso que ha encontrado cabida al interior de marcos institucionales y académicos tales como cátedras universitarias, post-títulos, post grados ${ }^{28}$ y políticas de Salud Pública. La inexisten-

28 Tanto la Universidad de Chile como la Pontificia Universidad Católica de Chile, imparten desde hace varios años programas de Magíster en Psicología Comunitaria y Psicología Social Comunitaria, respectivamente. 
cia de un programa de investigación sistemático hace sorprendente la referencia habitual y utilización sostenida de la Psicología Social Comunitaria como guía orientadora del desarrollo de Políticas Públicas.

\section{Sus memorias}

\section{- El recuerdo de sus orígenes}

El auge de los movimientos sociales latinoamericanos producido en los años 60 va acompańado de la transformación de algunas psicologías que vuelcan su interés en los sectores populares, desarrollando una concepción distinta de la salud-enfermedad, concibiendo a las personas como seres activos y generando una disciplina socialmente más sensible (Montero, 1994).

En ese contexto parecía casi inevitable criticar la distancia positivista que hasta el momento caracterizaba a la Psicología Social tradicional, desde lo que Ignacio Martín-Baró (1987) llamó la perspectiva crítica de los pueblos marginados. Era preciso un cambio disciplinar que acercara el investigador (agente de cambio social) a su pueblo, es decir, que lo despojara de su saber omnipotente y validara el saber popular. Los métodos tradicionales de Salud Mental, dominados por el paradigma positivista, debían ser transformados: se critica el énfasis en lo individual, así como la visión del sujeto pasivo, ${ }^{29}$ proponiendo en cambio trabajar en la comunidad, con la comunidad y para la comunidad. Martín-Baró sostiene que la Psicología Comunitaria en Latinoamérica es un paso inevitable y necesario en la manera de abordar las problemáticas sociales desde la disciplina psicológica. "Para que la psicología pueda contribuir a la liberación de los pueblos latinoamericanos, ella misma debe liberarse de su propia dependencia intelectual así como de su sumisión social” (Martín-Baró, 1987).

$\mathrm{Al}$ relatar sus orígenes, la Psicología Comunitaria Latinoamericana ha señalado como antecedente fundamental algunos movimientos políticos emancipatorios surgidos en la región: las experiencias participativas de desarrollo comunitario fundadas en el modelo de la Educación Popular inspirado en Paulo Freire (1970), Fals Borda (1959) y la Teología de la Liberación. A partir de ellos se asumen presupuestos tales como el compromiso con la realidad social, la necesidad de integrar teoría y práctica, la consideración del investigador como un agente de cambio social, la relación con el desarrollo de la conciencia social y el reconocimiento del carácter histórico y cultural de los fenómenos sociales. La Psicología Comunitaria se presenta así como una búsqueda de alternativas a las normas sociales estable-

29 Maritza Montero (1994) menciona la noción de sujeto pasivo, entendiéndolo como el sujeto de investigación que no adquiere protagonismo en el proceso de intervención del cual es parte, resultando ser un recipiente pasivo del saber del investigador. 
cidas, una defensa de los derechos fundamentales, un cuestionamiento al orden social instituido, y una voz crítica que emerge desde la Psicología oponiéndose a ella misma por no ser capaz de responder a las necesidades generadas por dichas condiciones sociales y menos contribuir a transformarlas.

La Psicología Comunitaria chilena, en cambio, reconstruye sus primeros pasos situando su origen en el área de la salud, específicamente en las propuestas de Psiquiatría Intracomunitaria de Juan Marconi y de Salud Mental Poblacional de Luis Weinstein. Ambas surgieron como un intento por abordar carencias específicas de los servicios de salud, y por superar las limitaciones que se presentaban en los servicios de salud mental. No eran modelos teóricos abstractos sino proyectos concretos de reforma y transformación de las instituciones, es decir, modelos de trabajo en salud y salud mental (Asún y otros, 1995).

La Psiquiatría Intracomunitaria, desarrollada entre 1968 y 1979, busca enfrentar los problemas de salud de mayor prevalencia a partir de los recursos humanos, materiales y culturales de la comunidad, en diálogo con los recursos humanos y técnicos de los servicios y universidades. Propone una mirada relativista cultural que respete diversos modos de vida, buscando superar la barrera cultural entre los Servicios Nacionales de Salud, la Universidad y la comunidad. De esta forma, un técnico estudia qué alternativas de solución de los problemas han sido entregadas por la población, para luego, respetándolas y aprovechando su propia dinámica social, enriquecerlas con el aporte científico y técnico. Así, el cambio es buscado a través de un dialogo creativo y respetuoso entre técnicos y comunidad y éste se implementa de acuerdo a los recursos disponibles en esta última (Marconi, 1970).

El modelo de Salud Mental Poblacional es una práctica de trabajo comunitario desarrollada a partir de 1963, que se plantea como superación de la medicina social aplicada en los servicios de atención de la época y busca desarrollar acciones de salud integrales que van más allá de las patologías, incorporando diversos niveles del ámbito poblacional. Weinstein critica el desconocimiento por parte de la psiquiatría tradicional de los aspectos estructurales de la sociedad (clases sociales) y sostiene que al no considerar los factores sociales y culturales opera como agente sostenedor del orden social establecido. Los programas buscan desarrollar la capacidad de autodirección, cuestionamiento y acción de la población; promover el cambio social y cultural; y generar participación.

Estas y otras propuestas de intervención social que enfatizan la participación y autogestión de la comunidad, aparecen en un contexto de auge de los movimientos sociales y políticos, ligadas a importantes proyectos de transformación social en un mundo de voluntades liberadoras. En un contexto de multiplicación y desarrollo activo de organizaciones sociales y de democratización progresiva de 
los servicios públicos, las voces críticas surgen en los más diversos ámbitos. Al interior de los hospitales, donde se detectaban los problemas de hacinamiento y mala calidad en la atención pública, surgen acciones lideradas por Marconi y Weinstein que reclaman ante dichas insuficiencias, sin pretender ser un movimiento de lucha o de revolución paradigmática sino buscando de manera fáctica la solución de problemas de salud.

Las narraciones que los psicólogos sociales comunitarios chilenos hacen de su historia sitúan sus orígenes en la medicina y no en la política, como en otras psicologías latinoamericanas de orientación similar. Considerando la importancia que los movimientos políticos disidentes tuvieron en nuestro país durante el siglo XIX, la efervescencia social de la época, las voluntades políticas liberadoras y los altos niveles de apoyo y participación de los distintos sectores sociales en diversos movimientos transformadores, es inverosímil pensar que la Psicología Social y sus desarrollos críticos no hayan sido marcados por ellos.

Al construir sus orígenes situándolos en la búsqueda de solución de problemas prácticos y no en la voluntad de transformación social, la Psicología Social Comunitaria enmarca las posibilidades y límites de su disidencia; se posiciona en el ámbito de lo fáctico, de las posibilidades técnicas de resolver problemas. Pero, ¿qué pasa con sus posibilidades de transformación social?, ¿puede ser la crítica en estas psicologías algo más que un presupuesto fundante? Hasta ahora dichas prácticas no han mostrado más que deseos, voluntades, valores y, por supuesto, un arduo e importante trabajo. Pero pretende más que eso, y sugiero que las narraciones que construye sobre ella misma le impiden constituirse en un proyecto político.

\section{- La retórica de la interrupción}

Psicólogos sociales comunitarios sostienen que la apertura de los profesionales de Salud Mental de los sesenta a incorporar a la comunidad y la dimensión social de los problemas de salud, sus elaboraciones teóricas e innovaciones prácticas, fueron interrumpidas por el Golpe de Estado de 1973. Hospitales, centros de salud y universidades pasaron a ser controlados por autoridades de confianza del régimen quienes ejercieron una censura que habría impedido seguir desarrollando dichos modelos críticos.

El régimen militar proscribe toda forma de acción social y política que se oponga a su autoridad. Dichas acciones son la que es perseguidas y sancionadas como amenazas a la seguridad nacional. Las prácticas represivas desarticulan los movimientos sociales instalando el miedo, la amenaza y la muerte como posibilidades ligadas al quehacer político. Las agrupaciones civiles se fragmentan y los debates políticos se mantienen en espacios de relativa clandestinidad. En ese 
contexto, las prácticas comunitarias deben ser replanteadas en términos de sus objetivos, viabilidad institucional y factibilidad de acción.

El modelo de economía neoliberal llevado a su extremo profundizó el empobrecimiento, la inestabilidad y precariedad laboral, la cesantía, y otros problemas que dificultaban la sobrevivencia cotidiana. Dichas urgencias, junto con los efectos del terrorismo de estado y las limitaciones para organizase, propiciaron la diversificación de las labores realizadas por los psicólogos comunitarios. Frente a la multiplicidad de necesidades y demandas urgentes de la población y tratando de combatir la precariedad laboral de toda aquella actividad relacionada con el trabajo social, en los años 80 ochenta se le asignaba el título de intervención psicosocial y/o comunitaria a cualquier labor realizada con sectores populares, prescindiendo de cualquier rigor en sus supuestos y fundamentos teóricos.

La Psicología Social Comunitaria se perfila durante dicho período como una propuesta contestataria y alternativa, esta vez con el sello -muchas veces explícito- de un compromiso asistencial o de participación como conciencia crítica (Olave y Zambrano, 1993). Busca organizar a la comunidad al margen de la institucionalidad oficial para resolver sus problemas de supervivencia y reconstruir el tejido social. Esas intervenciones se hicieron al margen de las instituciones del Estado, ya sea desde Organizaciones No Gubernamentales (O.N.G.) con financiamiento extranjero, o bien desde instituciones ligadas a la Iglesia Católica. Mariane Krause (1998) sostiene que se constituyó una forma de mundo alternativo, paralelo a la institucionalidad oficial, con identidad propia, visiones de conjunto particulares y tendencias específicas. Aunque el carácter alternativo de dicha institucionalidad posibilitaba un cierto grado de disidencia práctica y conceptual respecto de los saberes y de las políticas dominantes, su desarrollo se centra nuevamente en la resolución de problemas prácticos. No sólo se deja de lado la formulación de propuestas teóricas sino también los proyectos de transformación social que las definían como críticas al sistema dominante.

\section{- Después de la interrupción}

Desde 1989, la transición a la democracia prometió reorganizar globalmente la sociedad, abordando temas pendientes en materia de políticas sociales, atención en salud, leyes laborales y los efectos de las violaciones a los derechos humanos ocurridas durante el régimen militar. Los cambios eran urgentes: muchos temas que enfrentar y muchas necesidades que satisfacer, lo que no dejaba espacios para reflexionar en torno a los acontecimientos del país y mucho menos para pensar en profundidad las teorías que pudieran transformar a las psicologías dominantes. 
Una de las prioridades de los gobiernos post dictatoriales fue la promoción de la salud. Al buscar métodos para enfrentar gran cantidad de problemas y necesidades con recursos limitados e instituciones de salud saturadas, se encuentra con las propuestas de participación y autogestión promovidos por la Psicología Social Comunitaria desde sus inicios. Se recurrió entonces a profesionales con experiencia en dichas prácticas para la elaboración de las bases técnicas y científicas de una legislación que promoviera efectivamente el bienestar psicológico y psicosocial ( $\mathrm{Mi}$ nisterio de Salud, 1990). Para ello se buscó los conocimientos prácticos y teóricos que pudieran validar y estructurar sus políticas de acción. La Psicología Social Comunitaria se ve así inserta nuevamente en el ámbito institucional y gubernamental como protagonista activo de un proyecto político, siendo instada a sistematizar sus experiencias y a explicitar sus supuestos teóricos y metodológicos de manera de poder establecer políticas y criterios de intervención. Nuevamente, este conjunto de prácticas se encuentra frente a sus carencias teóricas y conceptuales. Y una vez más recurre a su saber fáctico, se sistematizan las acciones realizadas en el pasado buscando coherencias entre ellas, construyendo así un recorrido que pretendía dar cuenta del propio quehacer. La Psicología Social Comunitaria se reconstruye a sí misma situando su origen en las propuestas de Weinstein y Marconi, asumiendo dichos modelos como los más coherentes con las prácticas realizadas.

Actualmente, después de cuatro décadas de intervenciones psicosociales, las demandas siguen siendo amplias, variadas y urgentes. Frente a ellas, la Psicología Social Comunitaria sigue preguntándose por los fines de su quehacer y las respuestas no han dejado nunca de ser variadas, o más bien aisladas y referidas a las convicciones y posibilidades de los profesionales o las instituciones a cargo. Quien ha logrado establecer ejes comunes ha sido el Estado y desde principio de los noventa gran parte de las intervenciones psicosociales se realizan desde sus instituciones. Se crearon los llamados proyectos psicosociales, los Centros Comunitarios y de Salud Mental Familiar (COSAM), entre otros; existen múltiples y diversas instancias y programas de apoyo a iniciativas comunitarias; el gobierno anterior (del de Ricardo Lagos Escobar) dictó un decreto según el cual los proyectos municipales deben ser participativos.

Estamos entonces frente a un aparato estatal que promueve activamente (e incluso obliga) la realización de proyectos e intervenciones como los sostenidos por la Psicología Social Comunitaria durante décadas. Esta institucionalización de sus prácticas podría ser interpretada como un logro respecto de la marginalidad y precariedad de su funcionamiento anterior, pues el Estado es ahora un agente que busca resolver los problemas sociales del país a través del financiamiento de proyectos locales. En los setenta la crítica se levantó contra un sistema que no se hacía cargo de resolver los problemas de su sociedad y contra una psicología que 
tampoco lograba responder a ellos. Pero el contexto cambió: quienes criticaban están ahora a cargo de formular las políticas públicas, el Estado se hace cargo de financiar los proyectos que lo criticaban y la psicología logra articular un conjunto de prácticas que permanece vigente después de varias décadas.

De acuerdo a lo anterior, los y las psicólogos/as sociales comunitarios/as deberían estar satisfechos. Pero no lo están. Barranco y Díaz, analizando los discursos de la psicología comunitaria, sostienen que éstos se enmarcan dentro de un modelo ético que guía y caracteriza sus acciones. No se trataría de reglamentos institucionales, ni de fundamentos teóricos, ni de normas metodológicas, sino de un modelo valórico implícito que otorga cierta identificación particular a la Psicología Social Comunitaria. Este mismo horizonte ético lleva consigo una fuerte crítica al contexto, el cual pareciese postergar, coartar y restringir el campo de acción de la Psicología Comunitaria en la medida en que promueve valores contrarios a ella, es decir: individualismo, competitividad, consumo, etc. Las carencias teóricas y las indefiniciones del quehacer son ahora atribuidas a este contexto social y cultural que no permite ni el desarrollo ni la implementaciones de una ética comunitaria. El sistema político y cultural que inunda la cotidianidad del país resulta incompatible con los valores y supuestos que promueve la Psicología Comunitaria, no permitiendo su consolidación teórica ni su aplicación coordinada en terreno (Barranco y Díaz, 1998).

\section{Psicología y violencia política en Chile La necesidad de ser disidentes}

A partir del golpe de estado vivido en Chile en septiembre de 1973, se persiguió, exilió, torturó, asesinó, hizo desaparecer o ejerció alguna otra forma de represión sobre quienes eran una amenaza para el régimen militar (Organización de Estados Americanos, 1985). El sufrimiento de quienes vivieron directamente dichas situaciones los llevó a pedir ayuda a profesionales de salud mental quienes, al tratar de responder se encontraron con que ni los conocimientos ni las herramientas que habían adquirido en su formación (en psicología u otras disciplinas afines) les servían. Se enfrentaron a la necesidad de elaborar conceptos e implementar prácticas para abordar la vinculación entre el padecimiento de las personas y el contexto político, contribuyendo a aliviar el sufrimiento y los síntomas de quienes pedían ayuda. Los conceptos y las estrategias de intervención elaboradas han constituido lo que Agger y Jensen (1996) han llamado el modelo chileno. Este modelo se sigue utilizando hasta hoy, años después del término de la dictadura militar.

Preguntarse por la relación entre los sufrimientos personales y los procesos políticos fue desde el principio una necesidad que obligó a disentir de la psicología tradicional. Entender que los síntomas psicológicos eran producto de las 
relaciones sociales violentas y no de problemas internos implicó una fuerte crítica a las formas conceptuales dominantes en la disciplina. Buscar estrategias de intervención que fueran más allá del trabajo clínico, abarcando los espacios sociales y políticos causantes del problema, llevó a alejarse de los procedimientos habituales centrados en los individuos y a articular formas de acción que al mismo tiempo fueran psicológicas, sociales y políticas.

Los efectos de la represión política se hacían evidentes.: la sociedad se polariza en grupos contrapuestos: uno de ellos debe ser combatido y eliminado para que el otro pueda sobrevivir. Se introduce la muerte y lo siniestro como posibilidad asociada al quehacer político: participar en actividades políticas, sociales o sindicales implica la posibilidad real e inmediata de morir. La realidad de destrucción sobrepasa las fantasías, lo que introduce lo siniestro como un elemento de terror y miedo que persiste más allá de los hechos en sí (Lira, 1990).

La preocupación explícita por temas políticos, la defensa de los derechos humanos y el trabajo conjunto con sectores sociales perseguidos por el gobierno militar, configura una práctica psicológica que no solo es disidente con su propia disciplina sino que también lo es con la ideología impuesta en el país, y que muchas veces debió ser realizada en la clandestinidad. Una Psicología disidente, realizada por disidentes, en la disidencia. Elizabeth Lira sostiene que, en dicho contexto, fue necesario ser críticos de una Psicología que, pretendiendo tenerlas, no disponía de respuestas teóricas ni prácticas a las demandas de ayuda de las personas. Por otro lado, se trata de una psicología desarrollada en áreas críticas, es decir aquellas en las que se desafía la producción y reproducción de la vida como vida propiamente humana. Ambas maneras de entenderla implican una noción ética y política indisociable (Lira, 2002).

\section{La disidencia conceptual}

En el ámbito de la teoría, autores provenientes de distintas disciplinas y con enfoques muy diversos coincidieron en que la vivencia de situaciones de violencia extrema produce profundos efectos psíquicos y psicosociales. La conceptualización de estos efectos los lleva a ir más allá de lo psicológico, formulando una teoría que les permiteiera comprender los padecimientos ligados al contexto político. El eje de esta reflexión es el carácter histórico del padecimiento y la mayoría de ellas han sido agrupadas bajo la denominación de trauma psicosocial o trauma político (Montero, 1987).

Pensar el trauma históricamente implica, por un lado, considerar el carácter procesual de una experiencia que permanece en el tiempo y que posee distintos momentos de constitución, como es el caso de las dictaduras, transiciones y post transiciones a la democracia que han vivido muchos países latinoamericanos. Por otra parte, se hace necesario delimitar el terreno que define desde donde se pro- 
duce la situación traumática, es decir la represión política del estado, así como la especificidad que eso acarrea en sus efectos.

A partir de la crítica a las nociones tradicionales de trauma y al concepto de estrés post traumático que domina los estudios e intervenciones en contextos de violencia extrema, y centrándose en la idea de trauma como proceso histórico, se construyó una conceptualización que prometía dar cuenta de la complejidad del problema. Los logros han sido teórica y políticamente significativos: se contextualizó históricamente un proceso tradicionalmente considerado intra- psíquico, se rescató la dimensión social y política del problema, situándolo en el espacio de lo colectivo. Asumir dicha perspectiva y centrarse el trabajo profesional en la defensa de los derechos humanos, implicó una doble marginalidad: conceptual y política.

Las definiciones de trauma político destacan la importancia de diferenciar este tipo de padecimiento (y por lo tato de acción sobre él) debido al origen político del daño. Por lo tanto, la psicología de los derechos humanos constituiría un ámbito específico y diferente de acción en la medida en que trabaja con una población especial, que necesita ser tratada de manera especializada, por profesionales que deben tener una formación particular y experiencia con el tema (Piper, 1996).

\section{La disidencia práctica}

El origen de esta psicología disidente está en la necesidad de articular un ámbito de reflexión y de intervención distinto de la psicología tradicional, que logre dar cuenta de problemas que, al tener su origen en el ámbito de la política, serían distintos a los padecimientos psicopatológicos que preocupan normalmente a la psicología. En el ámbito de la conceptualización teórica, se destacó la especificidad del fenómeno de la violencia política y de sus efectos, diferenciándola de otras problemáticas. En el ámbito de la intervención se realizaron innovaciones técnicas y desarrollaron espacios de acción psicosocial que permitieran introducir la dimensión política al trabajo psicológico, entendiendo los síntomas en relación con las situaciones represivas que los produjeron. El proceso de construcción de un tipo de intervención diferente, en centros especializados, ligados la mayoría de las veces a organizaciones de defensa de los Derechos Humanos, va contribuyendo a la construcción de una categoría social hasta entonces desconocida para los chilenos, la de las víctimas de la represión política.

La especificidad de esta psicología se sostiene sobre el argumento del origen político de la vivencia (violaciones de Derechos Humanos por parte del Estado). El trabajar con los efectos de la violencia política (el apellido es importante) es lo que le daría el perfil a esta práctica profesional. Pese a la voluntad crítica de estos profesionales, la retórica utilizada produce el efecto no deseado de contri- 
buir a psicologizar y des-politizar otros procesos. Es decir, defender el carácter político de su práctica de la manera en como lo hacen implica diferenciarse de otras que, aunque estén centradas en temas similares no resultan tan políticas, promoviendo así la idea de la violencia como una práctica social sujeta a diferenciación de acuerdo al carácter público o privado de su origen. Las violaciones a los Derechos Humanos pueden ser consideradas un problema político en la medida en que su origen se encuentra en ese ámbito. En contraposición estarían las otras violencias, como la sexual o la intrafamiliar, que serían entendidas como problemas privados, cuyo origen no es visto ni como social ni como político (Piper, 1996).

Se produce una diferenciación artificial entre violencias políticas y privadas, situando la resolución de las primeras en el ámbito de lo público y de las segundas en el ámbito de lo privado. Por esta vía se está contribuyendo a legitimar la categoría problema privado como antagónica con lo político-público, determinando la existencia de una diferencia entre problemas políticos y sociales y problemas privados y subjetivos. Es obvio que construir esta diferencia no era el objetivo de quienes basaban su quehacer en la crítica a las dicotomías propias de la disciplina psicológica.

\section{- Las instituciones disidentes durante la dictadura}

Frente a la demanda masiva de ayuda que siguió al golpe de Estado, algunos sectores promovieron la formación de organizaciones de defensa de los Derechos Humanos. Aunque al principio no se ofrecía atención en salud mental su demanda llevó a crear redes de trabajo con grupos afines, políticamente confiables. Se prestó atención de emergencia a personas que experimentaban severos trastornos a raíz de las experiencias represivas padecidas.

Durante el periodo 1973-1990 se crearon y disolvieron múltiples organismos de Derechos Humanos, algunos de las cuales existen hasta la fecha. Con énfasis distintos algunos privilegiaron la documentación y la investigación, otros la reflexión y la educación, otros la asistencia jurídica, social, médica y psicológica. Pese a sus diferencias todos buscaban desarrollar un trabajo profesional y al mismo tiempo político, lo que los obligó a diferenciarse de sus roles profesionales establecidos. La disidencia fue el lugar de encuentro de dichas prácticas que se llevó a cabo, entre otras cosas, registrando y denunciando la violencia que imperaba en el país.

\section{- Les llamaban: programas de salud mental y Derechos Humanos}

En algunos de los organismos de apoyo a las víctimas funcionaron los entonces llamados programas de atención, que estaban integrados por médicos, y/o 
psicólogos, y/o psiquiatras y/o trabajadores sociales. ${ }^{30}$ Aunque los enfoques teóricos, estrategias de acción y posiciones políticas eran variadas, la mayor parte del trabajo fue concebido en un primer momento como atención de emergencia y luego fue derivando en enfoques y estrategias de intervención más complejos que integraban las distintas dimensiones del problema.

Durante 1989 y 1992, Agger y Jensen estudiaron a los organismos de derechos humanos que desarrollaron programas de salud mental durante la dictadura y observaron similitudes, tales como la caracterización de la población atendida y la contextualización social del trabajo realizado. Las coincidencias no tenían que ver con las modalidades de intervención implementadas sino con la manera de conceptualizar el daño, el que era entendido como producto de la situación social y política, diferenciándose así del modelo psicopatológico dominante en psicología. Son estas similitudes las que los llevaron a hablar de un modelo chileno (Agger y Jensen, 1996).

Un elemento común a los diversos programas fue la innovación de las categorías de registro de personas atendidas. A diferencia de los equipos de salud mental tradicionales, los criterios de clasificación utilizados no se relacionaban con las categorías psicopatológicas conocidas sino con las situaciones represivas padecidas por los sujetos. Esta identificación (de origen legal) diferencia el origen y tipo de padecimiento del sujeto o la familia, identificando la o las situaciones traumáticas padecidas. El tipo de categorización indica la relación establecida entre el diagnóstico de los consultantes y la situación represiva, enfoque que fue posteriormente desarrollado en ILAS y denominado diagnóstico situacional (Becker, Castillo y Díaz; 1991). Este tipo de diagnóstico difiere de los habituales en la medida en que se refiere al acontecimiento político que desencadena el problema, lo que busca garantizar que un problema de origen sociopolítico no sea encubierto por medio de la utilización de terminologías técnicas que lo transformen en un problema originado en alguna patología individual. También se diferencia del usado habitualmente en la atención que organismos internacionales dan a los refugiados políticos, quienes son diagnosticados según la categoría que la American Psychiatric Association define en sus Manuales de Diagnóstico Estadístico de Trastornos Mentales. EÉsta se denomina estréess postraumático y se establece a partir de la presencia de síntomas comunes posteriores a la vivencia de alguna situación de stress estrés extremo.

30 Comité de Cooperación para la Paz; Vicaría de la Solidaridad; FASIC (Fundación de Ayuda Social de las Iglesias Cristianas), PIDEE (Fundación para la Protección de la Infancia Dañada por los Estados de Emergencia); CINTRAS (Centro de Investigación y Tratamiento del Stress); CRESAM (Centro Regional de Salud Mental); CODEPU, (Comité de Defensa de los Derechos del Pueblo); Arzobispado de Concepción; ILAS; (Instituto Latinoamericano de Salud Mental y Derechos Humanos) (Lira y Piper,1996). 
Las intervenciones realizadas buscaron reparar las repercusiones de la represión política en el sujeto dañado (Lira y Weinstein, 1984), facilitando la integración de las dimensiones subjetivas y políticas de la propia identidad, enfatizando la necesidad de re-interpretar la experiencia vivida y de re-significar el daño como un hecho social.

La posibilidad de intervenir requería de un vínculo de confianza político que los profesionales llamaron en ese entonces vínculo comprometido (disfrazando su carácter ideológico) y que permitía a los distintos actores involucrados saberse posicionados en un mismo lugar: el de la disidencia política. Los objetivos de las intervenciones incluían la recuperación de proyectos políticos y la inserción de los sujetos en acciones colectivas de denuncia y oposición a la dictadura. Evitando nuevamente el riesgo que implicaba el carácter político de dichas definiciones y disfrazándolo con palabras técnicas, fue llamado recuperación del proyecto vital. Quienes desarrollaron y utilizaron esos términos conocían el carácter ideológico y provisional de sus procedimientos y terminologías. Sus móviles eran claramente políticos y contingentes. Sin embargo actualmente, años después, cuando el contexto político ha cambiado y la clandestinidad de prácticas y conceptos ha dejado de ser necesaria, esos términos siguen siendo utilizados en el trabajo con víctimas de la violencia política, esta vez sin la conciencia de su carácter contingente. Es evidente que lo que constituyó una práctica disidente en un contexto totalitario, es decir promover la participación y la recuperación de identidades colectivas que resultaban amenazantes para el régimen militar, dejó de serlo al transformarse las condiciones políticas y al dejar de ser amenazantes dichas acciones.

La práctica de la psicología en el ámbito de los derechos humanos es significada por quienes la realizan como una forma de militancia política, como una contribución a transformar las relaciones de injusticia de nuestra sociedad, como un ejercicio activo de desacuerdo frente a las condiciones socio políticas, y como un trabajo cuya realización trasciende el ámbito profesional. Su significado ético y político ha llevado a la mayor parte de ellos a asumir su trabajo como un compromiso militante en que han permanecido durante muchos ańos, a pesar de los riesgos que implicaba durante la dictadura. ${ }^{31}$ Las instituciones han sufrido muchos cambios, la mayoría de ellas se han cerrado, ${ }^{32}$ otras funcionan gracias al carácter

31 En el libro de Patricio Orellana y Elizabeth Quay Hutchinson se describe la persecución contra los organismos de Derechos Humanos en páginas 51-52 y en el anexo No 9. Los datos allí registrados se refieren solamente al período 1984- 1985 y registran asesinatos (2), secuestros y detenciones (169), homicidios frustrados (1), relegaciones (16). A ello se agrega que 11 miembros de instituciones de Derechos Humanos fueron torturados, 31 fueron severamente maltratados y hubo 38 casos de amedrentamientos y amenazas. No hay datos sistematizados sobre el período anterior.

32 Actualmente solo se mantienen funcionando CINTRAS, FASIC e ILAS. 
voluntario de sus miembros; sin embargo, muchos de los profesionales que empezaron a trabajar en el ámbito de los derechos humanos durante la dictadura lo siguen considerando un deber ético, y algunos lo han seguido realizando en los espacios de reparación abiertos por el Estado.

\section{- Cuando llegó la hora de reparar el daño}

El primer gobierno post -dictatorial creó la Comisión Nacional de Verdad y Reconciliación, cuyo objetivo fue establecer una verdad socialmente compartida y sobre las violaciones a los derechos humanos con resultado de muerte ocurridas durante la dictadura. El Informe de la Comisión (Comisión Nacional de Verdad y Reconciliación, 1991) constituye la expresión de esta vVerdad oficialmente reconocida por las autoridades gubernamentales

En esa misma época se fue construyendo el discurso de la reparación. Dicha metáfora, fue usada para referirse a un proceso psicosocial de restauración de lo dañado, es decir subjetividades, redes sociales, etc., lo que requería de la modificación de las condiciones políticas que habían posibilitado la violación de derechos humanos. La noción de reparación se instala usándose para referirse hacer referencia a una intervención que abarca a la sociedad en su conjunto, incluyendo dimensiones éticas, legales, políticas y psicológicas. (Martín-Baró, 1989).

En el contexto de dicha discusión, y a partir de la Verdad establecida por el Informe de la Comisión, se definió una política de reparación que se tradujo en la definición de un conjunto de medidas políticas sectoriales destinadas a enfrentar los problemas específicos derivados de las violaciones de Derechos Humanos.

Quienes trabajan en derechos humanos coincidieron en que, dado que el Estado persiguió y dañó a las personas, éste debía encargarse de reparar. Algunos de los profesionales que trabajaban en organizaciones de la Iglesia y Organizaciones no gubernamentales (ONGs) contribuyeron a elaborar una propuesta de salud mental para las víctimas ${ }^{33}$ que sirvió de base para algunas consideraciones, como la de las víctimas como traumatizados extremos. ${ }^{34}$ Dicha definición asume explícitamente el origen socio-político de los procesos de enfermedad y la necesidad de una contextualización histórico-social del tratamiento. En base a eso se recomienda (y luego implementa) la creación de un programa estatal de atención de salud integral, física y mental para aliviar, modificar y prevenir las consecuencias de las

33 La necesidad de establecer un programa para las víctimas de la violencia toma en cuenta la experiencia de los países europeos, en los que la demanda de atención de salud de personas que han sufrido persecución se ha mantenido durante más de 50 años después de ocurridos los acontecimientos.

34 La Comisión de Verdad y Reconciliación acogió para fundamentar su propuesta este concepto elaborado en ILAS (ILAS, 1991) 
violaciones de Derechos Humanos en los afectados y en sus grupos familiares (Informe de la Comisión Verdad y Reconciliación, 1991).

En la formulación de este proyecto, el Ministerio de Salud convocó a las organizaciones no gubernamentales que habían prestado atención a las víctimas de violaciones de Derechos Humanos durante el gobierno militar. Muchos de los profesionales que practicaron una psicología que se consideraba a sí misma disidente respecto de las políticas oficiales se trasladaron a los servicios del Estado buscando continuar desde allí sus acciones.

\section{El discurso disidente se transforma en una política de Estado}

Fue evidente para muchos que quienes debían contribuir a elaborar e implementar las políticas de reparación eran quienes habían participado en los organismos de derechos humanos durante la dictadura. El motivo era la confianza que los grupos de afectados podían tener en los compromisos éticos y políticos de los profesionales que llevaban años dedicados al tema.

La importancia que dichas políticas dieron al tema del daño psicológico y de lo especial de la atención que la población de víctimas necesitaba, abrió un debate sobre el tipo de profesional que debía trabajar en derechos humanos ${ }^{35}$ : ¿¿debía éste ser un experto en su disciplina (por ej. psicología) o más bien debía garantizar la confianza política de quienes demandaran su ayuda?

Para la psicología tradicional la respuesta a esta pregunta es obvia: aquellos problemas que pertenecen al orden de lo psicológico deben ser abordados mediante las técnicas apropiadas. Por lo tanto quien debe ejercer dichas técnicas es el profesional más experto. En contraposición a eso, quienes trabajan en derechos humanos destacan las motivaciones éticas y las opciones ideológicas del profesional en cuestión y la experticia técnica (aunque sigue siendo muy importante) sería una especificación secundaria al compromiso político.

Habrían entonces: problemas psicológicos / problemas políticos / y problemas psico-políticos. Estos últimos serían padecidos por personas que fueron víctimas de la violencia represiva y deben ser abordados por profesionales políticamente comprometidas con la de la justicia y la defensa de los derechos humanos. Nos encontramos así con una situación paradójica: quienes lucharon desde los inicios de la dictadura para romper con la marginalidad y la estigmatización impuesta por el gobierno militar y sus partidarios, promueven con su discurso esta misma diferenciación estigmatizadora y marginalizante.

Los problemas psicológicos tendrían que ser resueltos de manera técnica, los políticos por medio de transformaciones sociales y los psico-políticos de ambas

35 Para un análisis detallado de este debate ver Lira y Piper (1996) "Lo que dicen de su trabajo los profesionales del PRAIS". 
formas. La reparación tendría que darse en todos estos niveles, pero hasta ahora solo se han realizado un conjunto de medidas administrativas cuyos efectos aún no se perfilan claramente. El único espacio donde las medidas concretas parecen tener algún efecto es en ámbito de la atención individual, donde ha primado un enfoque psicológico que ha trascendido la voluntad política de los profesionales involucrados. La distancia entre la voluntad ética y política, por un lado y la efectividad de las intervenciones concretas por otro, resulta frustrante para las víctimas y para los profesionales que trabajan con ellas.

\section{¿Qué pasa hoy con las disidencias del pasado?}

He expuesto algunas notas de una psicología que se llamó a sí misma y es llamada por otros disidente. He mostrado los sentidos en los que lo han sido y cómo estos han ido cambiando. He planteado que el surgimiento de las psicologías críticas en Chile ha pasado por la articulación de las prácticas y reflexiones de la crítica de la Psicología Social Comunitaria y de la Psicología de los derechos humanos. He sostenido que éstas fueron expresión de ciertas condiciones sociales en las que fueron efectivamente alternativas a la psicología dominante y prácticas de resistencia política.

Pero, ¿qué pasa hoy con ellas? La pregunta requiere de un análisis de su efectividad histórica y contextual, considerando que no existe ninguna práctica que sea en esencia crítica y/o disidente. Todas lo son (o no) en distintos sentidos y en relación con las propuestas dominantes de ciertas épocas o contextos sociales, las que van cambiando en función de los equilibrios y desequilibrios de las relaciones de poder. No pretendo juzgar si dichas psicologías son hoy críticas, ni creo que eso sea posible. Más bien me interesa reflexionar sobre sus significados, límites y posibilidades; y me he encontrado con deseos y voluntades de cambio, convicciones y compromiso y, sobre todo un afecto compartido de rechazo a ciertas condiciones sociales, políticas y culturales.

Aunque la Psicología Social Comunitaria chilena disiente del sistema político vigente, no encuentra (porque no existe) un movimiento popular en el cual articular sus prácticas, lo que desperfila su disidencia, su ética la compromete con la resolución de problemas fácticos, los que muchas veces contribuyen a producir significados opuestos a su voluntad de transformación política. Sus dificultades para desarrollar un corpus teórico le quita fuerza a la crítica que hace a la ciencia y a la psicología dominante.

Aunque el discurso psicológico en derechos humanos fue en su origen disidente con su disciplina, ha construido un marco conceptual que contribuye a legitimar las dicotomías que criticaba, una práctica que buscaba articular acciones políticas se centra actualmente en el ejercicio técnico de su profesión, limitando 
su carácter político al tipo de población atendida y al contenido del trauma. Una psicología que en su origen fue disidente con el sistema social y que exigía su transformación, ya no busca articular prácticas alternativas, ni exige la transformación de la sociedad como una necesidad para la reparación social. Se acepta la reparación individual como el único ámbito de acción posible, aunque sea insuficiente y generadora de frustraciones para el conjunto de los actores involucrados.

La disidencia de estas psicologías es hoy un deseo y una voluntad. Ese es el punto de partida fundamental para poder construir un campo de acciones transformadoras, pero la realidad no se transforma con buenas intenciones sino con la articulación de prácticas diferentes. En la medida en que estas psicologías se han alejado de sus praxis políticas y se han acercado al campo de las técnicas psicológicas centradas en los sujetos individuales, han perdido un potencial crítico indispensable que es asumir que una práctica disidente es ante todo política. Y lo es cuando asume la transformación social como un hecho práctico inmediato, como algo inaplazable. Una Psicología Social Crítica debería estar dispuesta a considerar los efectos teóricos, éticos y políticos de afirmarse como un sujeto histórico y por lo tanto productor de realidad.

\section{Bibliografía}

Agger, I. y Jensen, S.B. (1996). Trauma y Cura en Situaciones de Terrorismo de Estado. Santiago de Chile: CESOC.

Asún, D., Krause, M., Aceituno, R., Alfaro, J., Morales, G. (1995). La Psicología Comunitaria en Chile-Análisis de sus características y perspectivas. En: Sánchez, E. y Wiesenfeld, E. (Editores). Psicología Social Comunitaria. Caracas: Tropikos.

Barranco, F. y Díaz, R. (1998). Psicología Comunitaria: memorias de un discurso. Tesis para optar al título de psicólogo, Universidad Diego Portales. Santiago, Chile.

Becker, D., Castillo, M.I. y Díaz, M. (1991). Trauma y Reparación Después de la Dictadura en Chile: Consideraciones Clínicas y Sociales. Trabajo presentado al $V$ Simposio Cultura y Situación Psicosocial en América Latina. Hamburgo: ILAS.

Comisión Nacional de Verdad y Reconciliación (1991). Informe de la Comisión Nacional de Verdad y Reconciliación. Santiago-Chile: Edición Oficial.

Fals Borda, O. (1959) Acción comunal en una vereda colombiana. Bogotá: Universidad Nacional de Colombia, Monografías sociológicas.

Freire, P. (1970) Pedagogía del Oprimido. Madrid: Siglo XXI Editores. (1979).

Ilas (1991). Derechos humanos: Todo es según el Dolor con que se Mira. SantiagoChile: ILAS.

Krause, M. y Jaramillo, A. (Editoras). (1998). Intervenciones Psicológico-Comunitarias en Santiago de Chile. Pontificia Universidad Católica de Chile. Primera Edición. Chile. 
Lira, E. y Weinstein, E. (1984). "Prefacio”. En E. Lira y E. Weinstein, Psicoterapia y Represión Política, México: Siglo Veintiuno, 1984, 11-16.

Lira, E. (1990). Subjetividad y política: los derechos humanos en la transición. Revista Persona y Sociedad: Justicia y Perdón. N1 2-3 ILADES.

Lira y Piper (Eds.). Reparación, Derechos Humanos y Salud Mental. Chile: CESOC Chile.

Lira, E. (2002). Notas Sobre Psicología Crítica. En Piper, I. (Comp.), Políticas, Sujetos y Resistencias. Cuadernos de Psicología Social / Magister en Psicología Social. Ed. ARCIS, Santiago de Chile.

Marconi, J. (1970). Esbozo de modelos de valor epidemiológico para la investigación y la acción en América Latina. En: Mariátegui, J. y Castro, A. (Editores). Epidemiología Psiquiátrica en América Latina. Editorial Acta fondo para la salud mental. Argentina.

Martín-Baró, I. (1984). Guerra y Salud Mental. En Psicología Social de la Guerra. San Salvador: UCA Editores, 1990, 23-40.

Martín-BAró, I. (1987). El reto popular a la psicología social en América Latina. Boletín de Psicología UCA. VI, 26. El Salvador.

Martín-Baró, I. (1988). La Violencia Política y la Guerra Como Causas del Trauma Psicosocial en El Salvador. En Psicología Social de la Guerra. San Salvador: UCA Editores, 1990, 66-84.

Ministerio de Salud (1990-1991). Políticas de Salud Mental. División de programas de Salud. Unidad de Salud Mental. Chile.

Montero, M. (1987). La Psicología Política en América Latina: 1956-1986 en: Psicología Política Latinoamericana. Ignacio Martín-Baró y Maritza Montero editores. Caracas-Venezuela: Ed. Panapo. 15-47.

Montero, M. (1994). Vidas paralelas: Psicología Comunitaria en Latinoamérica y en EE.UU. Fourth Biennal Conference. Society for Community Research and Action. Division 27 of the American Psychological Association. William and Mary College. Williamsburg. Estados Unidos.

Organización de Estados Americanos (1985). Informe sobre la situación de Derechos Humanos en Chile. Comisión Interamericana de Derechos Humanos. Doc 17. Washington, 1985.

Olave, R. M. y Zambrano, L. (Comps.). (1993). Psicología Comunitaria y Salud Mental en Chile. Editorial Universidad Diego Portales. Primera edición. Chile.

Piper, I. (1996). "Lo que dicen de su trabajo los profesionales del PRAIS". En: Lira y Piper (Eds.). Reparación, Derechos Humanos y Salud Mental. Ed. CESOC. Chile. Pags. 183-238.

SÁnchez Vidal, A. (1991). Psicología Comunitaria. Barcelona: Editorial PPU.

Weinstein, L. (1975). Salud mental y proceso de cambio: hacia una ideología de trabajo en prevención primaria. Buenos Aires: Editorial ECRO.

Fecha de recepción del artículo: 18 de diciembre de 2008.

Fecha de aceptación del artículo: 30 de diciembre de 2008. 